\title{
Uusia ruokintastrategioita broilerinuorikoiden ruokintaan
}

\author{
Petra Tuunainen ${ }^{1)}$, Erja Koivunen ${ }^{1)}$, Jarmo Valaja ${ }^{2)}$, Essi Tuomola ${ }^{3)}$ \\ ${ }^{1)}$ Maa- ja elintarviketalouden tutkimuskeskus MTT, Animale, 31600 Jokioinen, etuni- \\ mi.sukunimi@mtt.fi \\ ${ }^{2)}$ Helsingin yliopisto, Maataloustieteen laitos, Koetilantie 5, 00014 Helsingin yliopisto, etuni- \\ mi.sukunimi@helsinki.fi \\ ${ }^{3)}$ HK Agri Oy, Kariniementie, 27510 Eura, etunimi.sukunimi@hkagri.fi
}

\section{TIIVISTELMÄ}

Viimeisten 20 vuoden aikana broilerivanhempaispolven ruokinta on vaikeutunut. Broilerinuorikoiden ruokintaa joudutaan rajusti rajoittamaan, koska lintuhybridi on jalostettu tehokkaaksi rehunkäyttäjäksi. Rajoitetussa ruokinnassa vaarana on, että lintujen kilpailu rehusta ja stereotyyppinen käyttäytyminen ja liiallinen veden juonti lisääntyvät, mikä lisää parven epätasaisuutta. Elopainon oikea kehitys varhaisvaiheessa on erityisen tärkeää sillä, ellei varhaisvaiheen painotavoitteita saavuteta parven tasaisuus ja sukukypsyyden saavuttamiseen liittyvät luuston kehitys ja höyhenpeitteen kehitys häiriintyvät. Parvi ei tällöin saavuta parasta mahdollista tuotantotulosta ja jälkeläistuotanto jää alle tavoitellun. Tutkimuksen tavoitteena oli löytää optimaalista kasvua, hyvinvointia sekä taloudellista kannattavuutta edistäviä ruokintastrategioita broilerinuorikoille.

Kokeessa oli 1680 Ross 508 vanhempaispolven kanauntuvikkoa. Ruokintaryhmiä oli kokeessa neljä viikkoa kestävällä starttirehukaudella neljä, joista osalle linnuista annettiin prestarter- rehua neljän vuorokauden ikään asti (RV 19 \%; 19 \%+prestart; 21,6 \%; 21,6 \%+prestart). Kasvatusrehua linnut saivat neljän viikon iästä 18 viikon ikään asti. Kasvatusrehuvaiheessa ruokintakäsittelyjä oli kaksi; viljarehu ja kokonainen kauran jyvä sekä täysrehu.

Kokeen perusteella prestarter- rehustus ja starttirehun laimentaminen sekä kasvatusajan viljaruokinta soveltuivat hyvin broilerinuorikoiden ruokintaan. Prestarter- rehustuksella ja laimealla starttirehulla ruokittujen lintujen elopaino on startti- rehuvaiheen jälkeen pienempi kuin ilman prestarterrehua ja vahvempaa starttirehua syöneiden lintujen elopainot $(\mathrm{P}=0,003)$. Linnut kuluttavat tällöin hieman enemmän rehua $(\mathrm{P}<0,0001)$ ja niiden rehunhyötysuhde on suurempi $(\mathrm{P}<0,0001)$ verrattuna vahvempaa startti- rehua syöviin lintuihin. Lisäksi jo pienet rehumäärän lisäykset päivässä, voivat vähentää rehusta kilpailua ja lisätä lintujen kylläisyyden tunnetta ja näin ollen parantaa lintujen hyvinvointia. Myös parven tasaisuus on parempi prestarter- rehua saaneilla linnuilla $(\mathrm{P}=0,043)$ ja tasaisuus näyttäisi säilyvän koko kasvatusajan. Kasvatusrehuvaiheessa viljarehulla ja kokonaisella kauralla ruokittujen lintujen elopaino on kasvatusrehuvaiheen jälkeen pienempi kuin täysrehulla ruokittujen lintujen elopaino ( $\mathrm{P}=0,002)$. Viljarehuruokinta näyttäisi näin ollen sopivan hyvin kasvavien nuorikoiden ruokinnaksi. Lisäksi näyttäisi siltä, että prestarter- rehun jälkeen rehut voisivat olla vielä laimeampia kuin tässä kokeessa käytetyt. Laimeamman starttirehun rakeistaminen voi olla haastavaa, mutta viljarehu voisi olla laimeampaa tai kokonaista viljaa voisi ehkä syöttää enemmän kuin tässä kokeessa.

Asiasanat: viljaruokinta, broilerinuorikot, prestartti, kaura 


\section{JOHDANTO}

Viimeisten 20 vuoden aikana broilerivanhempaispolven ruokinta on vaikeutunut samalla kun lintuja on jalostettu paremmiksi rehunkäyttäjiksi (De Jong ym. 2009; Eitan \& Soller 2009). Broilerinuorikoiden ruokintaa joudutaan rajusti rajoittamaan. Tavoitteena on pitää vanhempaispolven linnut tavoitepainoisina koko niiden eliniän ajan. Elopainon kehitys varhaisvaiheessa on erityisen tärkeää sillä, ellei varhaisvaiheen painotavoitteita saavuteta parven tasaisuus, sukukypsyyden saavuttamiseen liittyvä luuston kehitys ja höyhenpeitteen kehitys häiriintyvät. Parvi ei tällöin saavuta parasta mahdollista tuotantotulosta ja jälkeläistuotanto jää alle tavoitellun.

On havaittu, että Suomessa vanhempaispolven lintuja karsitaan melko paljon parven epätasaisuuden takia. Rajoitetussa ruokinnassa lintujen kilpailu rehusta lisääntyy, jolloin osa yksilöistä saa vähemmän rehua, mikäli rehunjako ei ole riittävän tasaista. Myös yksilöiden välillä on eroja ruokahalun ja kilpailukyvyn suhteen. Epätasaisuus lisääntyy, koska lintujen elopaino ei kehity tasaisesti. Elopainoltaan liian pienet linnut karsitaan ennen munantuotannon alkua. Rajoitettaessa lintujen ruokintaa niiden epänormaalikäyttäytyminen esimerkiksi muun kuin ruoan nokkiminen ja veden juonti ja yleinen aktiivisuus lisääntyvät (De Jong ym. 2009; Merlet ym. 2005). Tutkimuksen tavoitteena oli löytää optimaalista kasvua, hyvinvointia sekä taloudellista kannattavuutta edistäviä ruokintastrategioita broilerinuorikoille.

\section{AINEISTOT JA MENETELMÄT}

Kokeessa oli 1680 Ross 508 -vanhempaispolven kanauntuvikkoa (starttirehu 12 ja kasvatusrehu 6 kerrannetta/käsittely). Untuvikot jaettiin 48 karsinaan $\left(2 \times 2 \mathrm{~m}^{2}\right)$ niin, että kussakin karsinassa oli 35 untuvikkoa. Koejärjestely oli $2 \times 4$ faktoriaalinen koe, jossa faktoreina olivat startti- ja (4) ja kasvatusruokinta (2). Kasvatusaikana linnut söivät sekä kasvatus- ja esihaudontarehua. Ruokintakäsittelyt (1 8) on esitetty taulukossa 1.

Taulukko 1. Ruokintakäsittelyt.

\begin{tabular}{|l|l|l|l|}
\hline Nro & Starttiruokinta & Kasvatusrehut* & Esihaudontarehut* $^{*}$ \\
\hline 1 & Startti 1 & Viljarehu 1 (85\%) + kaura (15\%) & Viljarehu 2 (85\%) + kaura (15\%) \\
\hline 2 & Startti 2 & Viljarehu 1 (85\%) + kaura (15\%) & Viljarehu 2 (85\%) + kaura (15\%) \\
\hline 3 & Startti 3 & Viljarehu 1 (85\%) + kaura (15\%) & Viljarehu 2 (85\%) + kaura (15\%) \\
\hline 4 & Startti 4 & Viljarehu 1 (85\%) + kaura (15\%) & Viljarehu 2 (85\%) + kaura (15\%) \\
\hline 5 & Startti 1 & Täysrehu 1 & Täysrehu 2 \\
\hline 6 & Startti 2 & Täysrehu 1 & Täysrehu 2 \\
\hline 7 & Startti 3 & Täysrehu 1 & Täysrehu 2 \\
\hline 8 & Startti 4 & Täysrehu 1 & Täysrehu 2 \\
\hline
\end{tabular}

Startti 1 = 11,80 ME MJ/kg $19 \%$ RV, Startti 2 = 10,56 ME MJ/kg $17 \%$ RV, Startti 3 = prestarter (12,2 ME $\mathrm{MJ} / \mathrm{kg}$ 21, $6 \% \mathrm{RV})+10,56 \mathrm{ME} \mathrm{MJ} / \mathrm{kg} 17 \% \mathrm{RV}$, Startti 4 = prestarter (12,2 ME MJ/kg 21, $6 \% \mathrm{RV})+9,32 \mathrm{ME}$ MJ/kg 15 \% 9,32 RV, Viljarehu 1 = 9,18 ME MJ/kg 12 \% RV, Täysrehu 1= 9,45 ME MJ/kg 12 \% RV, Viljarehu 2 = 10,2 ME MJ/kg 13 \% RV, Täysrehu 2 = 10,3 ME MJ/kg 13 \% RV

*Kasvatus- ja esihaudontarehuissa viljarehu (85 \%) + kokonainen kaura (15\%) vastasivat laskennallisesti täysrehua (puolet kauran määrästä täysrehussa korvattu kokonaisella kauralla viljarehuruokinnassa).

Rehut optimoitiin rehuvaiheittain sisältämään saman verran aminohappoja sekä vitamiini ja kivennäisaineita. Kokeessa noudatettiin Ross 508 -vanhempaispolven ruokintasuosituksia aminohappojen, vitamiinien ja kivennäisaineiden osalta.

Prestarter- rehua annetaan ruokintakäsittelyissä 3, 4, 7 ja 8 neljän vuorokauden ikään asti, jonka jälkeen annettiin käsittelyn mukaisia starttirehuja 28 vrk:n ikäisiksi asti. Prestarter- rehua ei kuitenkaan otettu pois ennen starttirehun syötön aloittamista. Muut ryhmät (käsittelyt 1, 2, 5 ja 6) saivat kokeen alusta alkaen käsittelyjen mukaisia starttirehuja neljän viikon ikään asti. Kasvatusrehua linnut saivat 28-105 vrk:n ikäisinä ja esihaudonta rehua 105-126 vrk:n ikäisinä. 
Elopainon kehitystä ja parven tasaisuutta seurattiin viikoittain yksilöpunnitusten avulla. Rehumäärät (g/lintu/pv) karsinoittain suunniteltiin elopainon (karsinan keskipainon) kehityksen mukaan. Seuraavan viikon rehumäärät laskettiin joka yksilöpunnituksen yhteydessä. Rehumääriä lisättäessä huomioitiin kuolleet/karsitut linnut.

\section{TULOKSET JA TULOSTEN TARKASTELU}

Koerehujen raaka-aineet sekä rehujen kemiallinen koostumus on esitetty taulukossa 2.

Taulukko 2. Koerehujen raaka-aineet (\%) ja rehujen kemiallinen koostumus (g/kg KA ellei toisin mainita).

\begin{tabular}{|c|c|c|c|c|c|c|c|c|}
\hline & \multirow[b]{2}{*}{ Prestarter } & \multicolumn{3}{|c|}{ Starttirehut } & \multicolumn{2}{|c|}{ Kasvatusrehut } & \multicolumn{2}{|c|}{ Esihaudontarehut } \\
\hline & & $\begin{array}{c}\text { Startti } \\
1\end{array}$ & $\begin{array}{c}\text { Startti } \\
2\end{array}$ & $\begin{array}{c}\text { Startti } \\
3\end{array}$ & Viljarehu 1 & Täysrehu 1 & Viljarehu 2 & Täysrehu 2 \\
\hline Vehnä & 30,78 & 35,29 & 42,83 & 38,8 & 26,47 & 22,5 & 48,16 & 40,94 \\
\hline Ohra & 0 & 6 & 19 & 9,5 & 0 & 0 & 0 & 0 \\
\hline Kaura & 0 & 15,3 & 0 & 0 & 17,65 & 30 & 17,65 & 30 \\
\hline Kuorittu kaura & 36 & 15,8 & 0 & 0 & 0 & 0 & 0 & 0 \\
\hline Kaurankuorijauho & 0 & 0 & 6,4 & 16,9 & 11,76 & 10 & 9,29 & 7,9 \\
\hline Vehnälese & 0 & 0 & 8,9 & 16,8 & 36,59 & 31,1 & 11,76 & 10 \\
\hline Soijarouhe & 28,2 & 22 & 17,6 & 13 & 2,35 & 2 & 5,65 & 4,8 \\
\hline Rypsiöljy & 1,4 & 1,75 & 1,4 & 1,25 & 1,18 & 1 & 1,18 & 1 \\
\hline Monokalsiumf. & 1,75 & 1,71 & 1,47 & 1,21 & 1,38 & 1,17 & 2,88 & 2,45 \\
\hline Ruokintakalkki & 1,2 & 1,23 & 1,37 & 1,49 & 1,53 & 1,3 & 2,07 & 1,76 \\
\hline Ruokasuola & 0,2 & 0,39 & 0,39 & 0,4 & 0,49 & 0,42 & 0,46 & 0,39 \\
\hline Kana-Hiven & 0,2 & 0,2 & 0,2 & 0,2 & 0,24 & 0,2 & 0,24 & 0,2 \\
\hline Broiler-Vita & 0,2 & 0,2 & 0,2 & 0,2 & 0,24 & 0,2 & 0,24 & 0,2 \\
\hline Metioniini & 0,03 & 0,05 & 0,07 & 0,06 & 0,03 & 0,03 & 0,14 & 0,12 \\
\hline Lysiini & 0,049 & 0,07 & 0,132 & 0,142 & 0,08 & 0,072 & 0,22 & 0,19 \\
\hline Treoniini & 0 & 0 & 0,019 & 0,025 & 0 & 0 & 0,05 & 0,044 \\
\hline Roxazyme G2 & 0,015 & 0,015 & 0,015 & 0,015 & 0,02 & 0,015 & 0,02 & 0,015 \\
\hline Kuiva-aine KA (\%) & 89,59 & 90,47 & 90,22 & 90,42 & 90,07 & 90,14 & 90,79 & 90,86 \\
\hline Raakavalkuainen & 239,9 & 209,7 & 194,6 & 168,2 & 142 & 139,3 & 158,9 & 148,4 \\
\hline Raakakuitu & 25,9 & 35,3 & 48,1 & 75,1 & 94,8 & 94,5 & 64,7 & 67,7 \\
\hline Raakarasva & 63,2 & 62,4 & 52,7 & 51,6 & 62,6 & 61,5 & 52,1 & 53 \\
\hline Tuhka & 67,7 & 70,5 & 66,8 & 66,2 & 74,6 & 69,6 & 82,9 & 80,7 \\
\hline Typettömät uuteaineet & 603,3 & 622,1 & 637,8 & 638,9 & 626 & 635,1 & 641,4 & 650,2 \\
\hline Metioniini & 5,13 & 5,19 & 4,23 & 3,86 & 3,13 & 3,13 & 4,43 & 4,46 \\
\hline Lysiini & 13,16 & 11,35 & 10,52 & 8,92 & 6,19 & 6,06 & 7,85 & 7,39 \\
\hline Treoniini & 9,06 & 8,21 & 7,27 & 6,36 & 4,77 & 4,65 & 5,66 & 5,37 \\
\hline Kalsium & 10,5 & 11,6 & 10,4 & 9,8 & 11,2 & 10 & 15,3 & 14,5 \\
\hline Fosfori & 9 & 8,9 & 8,5 & 8,1 & 9,2 & 8,6 & 12,3 & 11,4 \\
\hline
\end{tabular}

Lintujen elopainon kehitys ja kasvu sekä niiden tilastolliset merkitsevyydet on esitetty taulukossa 4. Lintujen rehunkulutus ja rehunhyötysuhde sekä niiden tilastolliset merkitsevyydet on taas esitetty taulukossa 5. Prestarter- rehu vaiheen $(0-4$ vrk) rehunkulutusta ja rehunhyötysuhdetta ei voitu määrittää, koska tältä ajalta vapaasti syötettyä rehua ei kerätty pehkulta pois.

Starttirehuvaiheessa (5-28 vrk) voimakkaista starttirehuja saaneet linnut (ryhmät 1 ja 2) olivat suurempia ja kasvu nopeampaa kuin laimeampia starttirehuja saaneet (ryhmät 3 ja 4). Laimeita starttirehuja saaneiden lintujen (ryhmät 2, 3 ja 4) rehunkulutus oli suurempi ja rehunhyötysuhde huonompi 
kuin voimakasta starttia saaneiden lintujen (ryhmä 1). Prestarttirehuja saaneet linnut (ryhmät 3 ja 4) olivat taas elopainoltaan pienempiä, kasvu hitaampaa ja niiden rehunkulutus oli suurempaa ja rehunhyötysuhde huonompi kuin tavallista starttirehua saaneilla linnuilla (ryhmä 2). Prestarttirehun jälkeen laimeampaa starttirehua saaneen ryhmän 4 linnut olivat vielä pienempiä ja kasvu hitaampi, rehunkulutus suurempi ja rehunhyötysuhde huonompi kuin prestarttirehun jälkeen voimakkaampaa starttirehua saaneilla linnuilla (ryhmä 3). Prestarttirehulla näyttäisi olevan siis vaikutusta sen syönnin lopettamisen jälkeenkin. Erityisesti prestarttirehu hillitsee kasvua, mutta huonontaa kuitenkin rehunhyötysuhdetta. Prestartin vaikutus tuntuu säilyvän kasvatus- ja esihaudontarehuvaiheissa samansuuntaisena. Prestarttirehuilla pystyttiin hillitsemään kasvua myös täysrehuruokinnassa. Sekä täysrehuja saaneiden, että viljarehua saaneiden ryhmissä ( 2 vs. 3 ja 4 sekä 6 vs. 7 ja 8 ) prestarttia saaneilla linnuilla kasvu oli hitaampaa kuin pelkkää starttirehua saaneella ryhmällä.

Viljarehuilla ei saavutettu tilastollisia eroja eri ruokintaryhmien välille. Ainoastaan havaittiin että kasvatusrehuvaiheessa (29-105 vrk) viljarehuilla ruokitut linnut (ryhmät 1-4) olivat pienempiä ja niiden kasvu oli hitaampaa kuin täysrehulla ruokituilla linnuilla (ryhmät 5-8). Koko kasvatusaikaa tarkastellessa starttirehuvaiheessa prestarter- rehua ja laimeinta starttia syöneet linnut (ryhmät 4 ja 8) kasvoivat enemmän kuin ryhmien linnut, jotka saivat toiseksi laimeinta starttirehua koko starttirehuvaiheen ajan (ryhmät 2 ja 6). Lisäksi ryhmien 4 ja 8 linnut, jotka saivat prestarter- rehun jälkeen laimeampaa starttirehua kuin ryhmät 3 ja 7 linnut kasvoivat hieman enemmän kuin ryhmien 3 ja 7 linnut. Koko kasvatusajan tuloksia katsottaessa eri ruokintaryhmien välillä ei havaittu tilastollisesti merkitseviä eroja rehunkulutuksessa.

Ruokintaryhmien elopainon tasaisuutta mitattiin laskemalla niiden lintujen määrä (\%) ruokintaryhmässä, joiden elopaino oli keskielopaino +/-10 \% (taulukko 3). Ryhmien tasaisuus oli ensimmäisen neljän vuorokauden aikana hyvä. Yli 70 \%:lla kaikkien ryhmien linnuista elopaino jäi määriteltyyn rajaan. 4 vrk:n ikäisillä linnuilla prestarter- rehua saaneilla ryhmillä (ryhmät 3 ja 4) parven tasaisuus oli parempi kuin tavallista startti- rehua saaneella ryhmällä (ryhmä 2). Sama ero pystytään havaitsemaan myös 28 vrk:n ikäisillä linnuilla, kun startti- rehuvaihe loppui. Parvien tasaisuus heikkeni huomattavasti kasvatusrehuvaiheessa. Enää noin puolet kaikkien ryhmien linnuista jäi määritellyn rajan sisäpuolelle. Tilastollisesti merkitsevää eroa myöhempien rehuvaiheiden tasaisuudessa ei havaittu, vaikka prestarter- rehua saaneiden ryhmien (ryhmät 3, 4, 7 ja 8) tasaisuus onkin keskiarvojen perusteella hiukan tavallista starttia saaneita ryhmiä (ryhmät 1, 2, 5 ja 6) parempi.

Taulukko 3. Lintujen elopainon tasaisuus ruokintaryhmässä (\% linnuista, joiden elopaino jää määriteltyyn ryhmään: elopainon ka +/-10\%)

\begin{tabular}{lcccccccccc}
\hline Ruokintaryhmä & $\mathbf{1}$ & $\mathbf{2}$ & $\mathbf{3}$ & $\mathbf{4}$ & $\mathbf{5}$ & $\mathbf{6}$ & $\mathbf{7}$ & $\mathbf{8}$ & SEM & $\mathbf{C 3}$ \\
& & & & & & & & & & \\
\hline $\begin{array}{l}\text { Tasaisuus (\% } \\
\text { linnuista) }\end{array}$ & & & & & & & & & & \\
0 vrk & 86,2 & 83,6 & 84 & 82,9 & & & & & 1,56 & \\
4 vrk & 78,6 & 71,7 & 78,1 & 77,6 & & & & & 1,99 & $*$ \\
28 vrk & 60,2 & 50,5 & 57,1 & 60 & & & & & 3,17 & $*$ \\
105 vrk & 47,1 & 47,6 & 59,5 & 50,5 & 53,3 & 56,7 & 57,1 & 52,4 & 4,32 & \\
126 vrk & 49,5 & 47,1 & 52,4 & 53,8 & 46,2 & 51,9 & 58,1 & 49 & 3,89 & \\
\hline
\end{tabular}

${ }^{\mathrm{a}-\mathrm{c}}$ Keskiarvot, joilla on yhteinen yläindeksi, eivät poikkea toisistaan tilastollisesti merkitsevästi 5 \% riskitasolla (Tukeyn testi)

Ruokintaryhmien eroja testattiin seuraavilla ortogonaalisilla kontrasteilla: C1 = viljarehuruokinta vs. täysrehuruokinta; C2 = ryhmä 1 (5) vs. ryhmät 2, 3, 4, (6, 7, 8); C3 = ryhmä 2 (6) vs. ryhmät 3, 4, (7, 8); C4 = ryhmä 3, (7) vs. ryhmä 4, (8); C5 = C1 × C2; C6 = C1 × C3 ja C7 = C1 × C4. Taulukossa on esitetty vain tilastollisesti merkitseviä eroja saaneiden kontrastien arvot.

*** $\mathrm{P}<0,0001$, ** $\mathrm{P}<0,01$, * $\mathrm{P}<0,05$ ja o $\mathrm{P}<0,10$ 
Taulukko 4. Nuorikoiden painon kehitys (elopainot sekä kasvut (g)) sekä painon kehityksen tilastolliset merkitsevyydet.

\begin{tabular}{|c|c|c|c|c|c|c|c|c|c|c|c|c|c|}
\hline Ruokintaryhmä & 1 & 2 & 3 & 4 & 5 & 6 & 7 & 8 & SEM & $\mathrm{C1}$ & C2 & $\mathrm{C3}$ & C4 \\
\hline \multicolumn{14}{|l|}{ Elopaino } \\
\hline 0 vrk & 42,5 & 42,8 & 42,3 & 43 & & & & & 0,17 & & & & $* *$ \\
\hline 4 vrk & 86,3 & 85,9 & 86,1 & 86,8 & & & & & 0,53 & & & & \\
\hline 28 vrk & $517,9^{\mathrm{ab}}$ & $522,4^{\mathrm{a}}$ & $507,9^{\mathrm{b}}$ & $480,7^{c}$ & & & & & 3,84 & & $* *$ & $* * *$ & $* * *$ \\
\hline 105 vrk & $1597,7^{\mathrm{ab}}$ & $1587,3^{\mathrm{ab}}$ & $1581,6^{\mathrm{b}}$ & $1616,6^{\mathrm{ab}}$ & $1626,6^{\mathrm{a}}$ & $1613,4 \mathrm{a}^{\mathrm{b}}$ & $1599,7^{\mathrm{ab}}$ & $1625,7^{\mathrm{a}}$ & 8,78 & $* *$ & & & $* * *$ \\
\hline 126 vrk & 1968,2 & 1948,6 & 1961,1 & 1995 & 1975 & 1947,8 & 1971,9 & 1995,5 & 12,56 & & & $* *$ & $*$ \\
\hline \multicolumn{14}{|l|}{ Kasvu } \\
\hline 0 - 4 vrk & 43,9 & 43,1 & 43,8 & 43,7 & & & & & 0,51 & & & & \\
\hline 5 - 28 vrk & $431,6^{\mathrm{a}}$ & $436,5^{\mathrm{a}}$ & $421,8^{\mathrm{a}}$ & $393,9^{\mathrm{b}}$ & & & & & 4,01 & & $* *$ & $* * *$ & $* * *$ \\
\hline $29-105$ vrk & $1080,9^{\mathrm{cd}}$ & $1060,1^{d}$ & $1077,4^{\mathrm{cd}}$ & $1135,4^{\mathrm{ab}}$ & $1113,9^{\mathrm{abc}}$ & $1095,6^{\mathrm{bcd}}$ & $1088,1^{\mathrm{cd}}$ & $1145,4^{\mathrm{a}}$ & 9,26 & $* *$ & & $* * *$ & $* * *$ \\
\hline $106-126$ vrk & 370,5 & 361,2 & 379,5 & 378,4 & 348,4 & 334,5 & 372,2 & 369,9 & 14,48 & & & $*$ & \\
\hline 0 - 126 vrk & 1925,5 & 1905,6 & 1918,5 & 1951,9 & 1935,6 & 1905 & 1929,8 & 1952,5 & 12,64 & & & $* *$ & $*$ \\
\hline
\end{tabular}

${ }^{\mathrm{a}-\mathrm{c}}$ Keskiarvot, joilla on yhteinen yläindeksi, eivät poikkea toisistaan tilastollisesti merkitsevästi 5 \% riskitasolla (Tukeyn testi)

Ruokintaryhmien eroja testattiin seuraavilla ortogonaalisilla kontrasteilla: C1 = viljarehuruokinta vs. täysrehuruokinta; C2 = ryhmä 1 (5) vs. ryhmät 2, 3, 4, (6, 7, 8); C3 = ryhmä 2 (6) vs. ryhmät 3, 4, (7, 8); C4 = ryhmä 3, (7) vs. ryhmä 4, (8); C5 = C1 × C2; C6 = C1 × C3 ja C7 = C1 × C4. Taulukossa on esitetty vain tilastollisesti merkitseviä eroja saaneiden kontrastien arvot.

$* * * \mathrm{P}<0,0001, * * \mathrm{P}<0,01, * \mathrm{P}<0,05$ ja o $\mathrm{P}<0,10$

Taulukko 5. Nuorikoiden rehunkulutus (g/lintu/pv), vedenkulutus (ml/lintu/pv) ja rehunhyötysuhde (kg rehua/ kg kasvu) ja rehunkulutuksen ja rehunhyötysuhteen tilastolliset merkitsevyydet.

\begin{tabular}{|c|c|c|c|c|c|c|c|c|c|c|c|c|}
\hline Ruokintaryhmä & 1 & 2 & 3 & 4 & 5 & 6 & 7 & 8 & SEM & $\mathrm{C} 2$ & C3 & $\mathrm{C4}$ \\
\hline \multicolumn{13}{|l|}{ Rehunkulutus } \\
\hline $\begin{array}{l}0-4 \mathrm{vrk} \\
5-28 \mathrm{vrk}\end{array}$ & $\begin{array}{l}15,9 \\
29,9^{\mathrm{c}}\end{array}$ & $\begin{array}{c}16 \\
32,1^{\mathrm{b}}\end{array}$ & $\begin{array}{c}16 \\
31,7^{\mathrm{b}}\end{array}$ & $\begin{array}{c}16 \\
33,1^{\mathrm{a}}\end{array}$ & & & & & $\begin{array}{l}0,05 \\
0,16\end{array}$ & $* * *$ & $* * *$ & $* * *$ \\
\hline $\begin{array}{l}29-105 \text { vrk } \\
106-126 \text { vrk }\end{array}$ & $\begin{array}{l}57,5^{\mathrm{b}} \\
67,6\end{array}$ & $\begin{array}{l}58,2^{\mathrm{b}} \\
68,8\end{array}$ & $\begin{array}{l}58,0^{\mathrm{b}} \\
69,1\end{array}$ & $\begin{array}{l}59,9^{\mathrm{a}} \\
69,7\end{array}$ & $\begin{array}{l}58,0^{b} \\
67,9\end{array}$ & $\begin{array}{l}58,0^{\mathrm{b}} \\
67,3\end{array}$ & $\begin{array}{l}58,4^{b} \\
68,8\end{array}$ & $\begin{array}{l}60,4^{\mathrm{a}} \\
69,4\end{array}$ & $\begin{array}{l}0,28 \\
1,29\end{array}$ & $* * *$ & $* * *$ & $* * *$ \\
\hline 0 - 126 vrk & 52,3 & 54,2 & 54 & 55,7 & 53,1 & 54 & 54,6 & 56,4 & 1,27 & & & \\
\hline \multicolumn{13}{|l|}{ Rehunhyötysuhde } \\
\hline $\begin{array}{l}0 \text { - } 4 \text { vrk } \\
5 \text { - } 28 \text { vrk } \\
29-105 \text { vrk }\end{array}$ & $\begin{array}{c}1,8 \\
1,7^{\mathrm{c}} \\
4\end{array}$ & $\begin{array}{l}1,9 \\
1,8^{b} \\
4,3\end{array}$ & $\begin{array}{c}1,8 \\
1,8^{b} \\
4,2\end{array}$ & $\begin{array}{c}1,8 \\
2,0^{\mathrm{a}} \\
4,2\end{array}$ & 4,1 & 4,1 & 4,1 & 4,1 & $\begin{array}{l}0,02 \\
0,13 \\
0,07\end{array}$ & $\begin{array}{c}* * * \\
0\end{array}$ & $* * *$ & $* * *$ \\
\hline $\begin{array}{l}106-126 \text { vrk } \\
0-126 \text { vrk }\end{array}$ & $\begin{array}{c}2 \\
2,9\end{array}$ & $\begin{array}{c}1,8 \\
3\end{array}$ & $\begin{array}{l}2,3 \\
3,1\end{array}$ & $\begin{array}{c}1,8 \\
3\end{array}$ & $\begin{array}{l}1,8 \\
2,9\end{array}$ & $\begin{array}{l}2,1 \\
3,1\end{array}$ & $\begin{array}{c}2,4 \\
3,18\end{array}$ & $\begin{array}{l}2,1 \\
3,2\end{array}$ & $\begin{array}{l}0,23 \\
0,12\end{array}$ & 0 & & o \\
\hline
\end{tabular}

$\overline{\mathrm{a}-\mathrm{c}}$ Keskiarvot, joilla on yhteinen yläindeksi, eivät poikkea toisistaan tilastollisesti merkitsevästi 5 \% riskitasolla (Tukeyn testi) 
Ruokintaryhmien eroja testattiin seuraavilla ortogonaalisilla kontrasteilla: C1 = viljarehuruokinta vs. täysrehuruokinta; C2 = ryhmä 1 (5) vs. ryhmät 2, 3, 4, (6, 7, 8); C3 = ryhmä 2 (6) vs. ryhmät 3, 4, (7, 8); C4 = ryhmä 3, (7) vs. ryhmä 4, (8); C5 = C1 × C2; C6 = C1 × C3 ja C7 = C1 × C4. Taulukossa on esitetty vain tilastollisesti merkitseviä eroja saaneiden kontrastien arvot.

*** $\mathrm{P}<0,0001, * * \mathrm{P}<0,01, * \mathrm{P}<0,05$ ja o $\mathrm{P}<0,10$

\section{JOHTOPÄÄTÖKSET}

Tämän kokeen perusteella prestarter- rehustuksella ja laimealla starttirehulla voidaan saada aikaan hyvä nuorikoiden painon kehitys neljän ensimmäisen kasvatusviikon aikana. Myös parven tasaisuus on parempi prestarter- rehua saaneilla linnuilla ja tasaisuus näyttäisi säilyvän koko kasvatusajan. Edellä mainitulla tavalla ruokittujen lintujen elopaino on startti- rehuvaiheen jälkeen pienempi kuin ilman prestarter- rehua ja vahvempaa starttirehua syöneiden lintujen elopaino. Linnut kuluttavat tällöin hieman enemmän rehua ja niiden rehunhyötysuhde on suurempi verrattuna vahvempaa startti- rehua syöviin lintuihin. Lisäksi jo pienet rehumäärän lisäykset päivässä voivat vähentää rehusta kilpailua ja lisätä lintujen kylläisyyden tunnetta ja näin ollen parantaa lintujen hyvinvointia.

Kasvatusrehuvaiheessa viljarehulla ja kokonaisella kauralla ruokittujen lintujen elopaino on kasvatusrehuvaiheen jälkeen pienempi kuin täysrehulla ruokittujen lintujen elopaino. Viljarehuruokinta näyttäisi näin ollen sopivan hyvin kasvavien nuorikoiden ruokinnaksi.

Lisäksi näyttäisi siltä, että rehut prestarter- rehun jälkeen rehut voisivat olla vielä laimeampia kuin tämän kokeen rehut. Laimeamman starttirehun rakeistaminen voi olla haastavaa, mutta viljarehu voisi olla laimeampaa tai kokonaista viljaa voisi ehkä syöttää enemmän kuin tässä kokeessa.

Tässä kokeessa kuolleiden ja karsittujen lintujen määrä eivät eronneet ryhmien välillä, joten näiden tässä kokeessa tutkitut ruokintastrategiat prestarter- rehu, rehunlaimennus ja viljarehuruokinta soveltuvat hyvin kasvavien broileriemojen ruokintastrategioiksi.

\section{KIRJALLISUUS}

De Jong, I. C. \& Guémené D. 2009. Welfare issues in broiler breeders. Teoksessa: Poultry Welfare Symposium, Cervia, Italy, 18-22.5.2009: 120-127 s.

Eitan , Y. \& Soller, M. 2009. Problems associated with broiler breeder entry into lay: a review and hypothesis. World's Poultry Science Journal 65: 641-648 s.

Merlet F., Puterflam J., Faure J.M., Hocking P.M., Magnusson M.S. \& Picard M. 2005. Detection and comparison of time patterns of behaviours of two broiler breeders genotypes fed ad libitum and two levels of feed restriction, Applied Animal Behaviour Science 94: 255 - 271. 